\title{
Factors influencing decisions to admit or refuse patients entry to a South African tertiary intensive care unit
}

\author{
P D Gopalan, MB ChB, FCA (SA), Critical Care (SA); K de Vasconcellos, MB ChB, FCA (SA), Cert Critical Care (SA) \\ Discipline of Anaesthesiology and Critical Care, School of Clinical Medicine, College of Health Sciences, Nelson R Mandela School of Medicine, \\ University of KwaZulu-Natal, Durban, South Africa; and Intensive Care Unit, King Edward VIII Hospital, Durban, South Africa
}

Corresponding author: P D Gopalan (gopalan@ukzn.ac.za)

\begin{abstract}
Background. When critically ill patients with life-threatening conditions need urgent, expensive, life-sustaining care, admission and triage decision-making may be extremely challenging as critical care practitioners strive to balance these high-stakes, high-stress, time-sensitive decisions against a limited resource. The factors affecting the decision to admit or refuse a patient entry to an intensive care unit (ICU) have not been described in the South African (SA) context.

Objectives. To identify and describe the factors that influence ICU triage decision-making for patients referred to a regional/tertiary facility for intensive care.

Methods. A retrospective review of recorded data from January 2014 to December 2017 was conducted for all referrals to the 12-bed, intensivist-led, closed general ICU at King Edward VIII Hospital, an 800-bed tertiary public facility in KwaZulu-Natal Province, SA. Data were extracted to identify factors associated with the decision to admit or refuse patients referred to the unit. Significant factors on univariate analysis were then included in a multivariable analysis using binary logistic regression to identify significant independent factors. Results. A total of 4469 referrals were received over the 48-month period studied. Of these, 507 (11.3\%) were withdrawn before a final decision of acceptance or refusal and 94 (2.1\%) had an unknown outcome, leaving 3868 referrals where an acceptance/refusal decision was made as our study cohort. Of these, $38.7 \%$ were refused admission. The commonest reason for refusal (57.0\%) was assessment of the patient as 'too sick' by the admitting specialist. Multivariable analysis identified age, referring discipline as medicine, poor or unknown premorbid functioning, and comorbidities of HIV, malignancy and cardiac failure as significant factors for refusal of admission to the ICU. Referrals were significantly more likely to be accepted from private institutions, and if the comorbidity was asthma or psychiatric disease.

Conclusions. A better understanding of factors affecting ICU admission/refusal decisions will allow for a more effective and appropriate referral process and more rational utilisation of scarce ICU resources. Further prospective studies are necessary to elucidate fully the impact of various other factors.
\end{abstract}

S Afr Med J 2019;109(9):645-651. https://doi.org/10.7196/SAMJ.2019.v109i9.13678

When critically ill patients with life-threatening conditions need urgent, expensive, life-sustaining care, admission and triage decision-making may be extremely challenging as critical care practitioners strive to balance these high-stakes, high-stress, time-sensitive decisions against a limited resource. In an ideal situation, all patients likely to benefit in respect of morbidity or mortality from their admission into an intensive care unit (ICU) should be admitted. As available resources are invariably outstripped by large demands, rationing of these resources and triaging of patients has to occur. ${ }^{[1]} \mathrm{A}$ difficult balance has to be achieved between undertriage, where patients likely to substantially benefit from ICU admission are not afforded this opportunity, leading to adverse outcomes, and overtriage, where patients who are unlikely to benefit from intensive care are admitted, resulting in an inappropriate utilisation of resources. ${ }^{[1]}$

Rising healthcare costs in a low- to middle-income country such as South Africa (SA) have necessitated a shift in spending towards primary and preventive care at the expense of more specialised services such as critical care. ${ }^{[2]}$ The escalating demand for critical care outstrips the available resources for the provision of such care. In SA, only $23 \%$ of public hospitals have ICUs, with ICU beds only accounting for $1-2 \%$ of all acute care beds. ${ }^{[3]}$ In KwaZulu-Natal (KZN) Province, the ICU bed-to-population ratio is 1:32 000. ${ }^{[3]}$ Both the proportion of beds and the ratio to population are markedly substandard in comparison with high-income countries. ${ }^{[3-5]}$ Choosing the most appropriate patients for such limited resources is therefore vital.
There are limited SA data available regarding the pattern of patient referrals to ICUs, refusal rates, and the factors impacting on the decision to accept or refuse a patient admission to an ICU. A dated audit revealed an ICU refusal rate of $47 \%$, with $21 \%$ of patients refused admission because the ward was full, $18 \%$ because treatment was deemed to be futile, and $8 \%$ because the duty consultant was of the opinion that intensive care was inappropriate and the patient could be treated safely in a general ward. ${ }^{[6]}$ A subsequent audit showed ICU refusal rates of $38 \%$ and $22 \%$ for two hospitals, reporting that $55 \%$ and $89 \%$ of refusals, respectively, were because no bed was available. ${ }^{[7]} \mathrm{A}$ more recent study showed a refusal rate of $28 \%$, with $53.6 \%$ of these patients considered too well and $46.4 \%$ too severely ill to benefit. ${ }^{[8]}$

Various factors contributing to triage decisions have been identified in the literature. One classification suggests that such factors may be viewed as patient, physician and contextual. ${ }^{[9]}$ Contextual factors include ICU characteristics such as current bed availability, appropriate equipment and nursing expertise. Patient factors include patient characteristics (such as functional capacity) and comorbidities, and characteristics of the acute illness in respect of severity, reversibility, response to therapy and predicted quality of life after ICU discharge. Physician factors focus on the characteristics of the person making the decision and may include experience, personality, mood and biases. The factors impacting on the decision to admit or refuse a patient to an ICU have not been described in the SA context. 


\section{Objectives}

To identify and describe the factors that influence ICU triage decision-making for patients referred to a tertiary facility for intensive care.

\section{Methods}

The study was conducted in the 12-bed general ICU at King Edward VIII Hospital, an 800-bed tertiary public facility in KZN, SA. The intensivist-led unit is closed and usually has a 1:1 nurse-to-patient ratio. All referrals are reviewed by the critical care team with the final decision on admission made by the on-call consultant. Intrahospital referrals are usually physically assessed by a member of the ICU team. Referrals from outside the hospital are usually via a telephonic consultation. Patients referred to the ICU for whom decisions are not immediately made are marked as 'pending review', awaiting further information and/ or on-site management before the definitive admission/refusal decision.

A retrospective review of recorded data from January 2014 to December 2017 was conducted for all referrals to the unit. Referrals are routinely recorded on pro forma referral forms that are manually stored in the unit and subsequently captured onto an Excel version 16.16.11 spreadsheet (Microsoft, USA), which served as the data source. The pro forma captures a panel of clinical and physiological parameters of the patient being referred as well as administrative data on the referring doctor and unit. After ethics approval (University of KwaZulu-Natal Biomedical Research Ethics Committee ref. no. BE 291/17) and institutional permission, a process of data verification was conducted after which data were extracted in the following fields: admission date, patient age, patient sex, race, referring hospital, referring discipline, primary diagnosis (medical, surgical or obstetrics and gynaecology), source of sepsis, premorbid functional status, HIV status, comorbidities, outcome of the consult, reasons for refusal, outcomes of patients refused, outcomes of accepted consults, reasons for withdrawals, and readmissions. Options for reasons for refusal were one of three: 'no bed' (i.e. unit full but the patient would have been accepted had there been a bed); 'too well' (where the patient was deemed too well and the bed was not needed as the patient could be managed effectively outside the ICU); and 'too sick' (where benefit was deemed to be minimal, i.e. triage, or absent, i.e. futile). Race is not routinely recorded as part of the referral and was inferred from patient names.
Data were collected retrospectively and, with no interventions instituted, reflected unit practice at that time. Data were then transferred to SPSS Statistics, version 25.0 (IBM, USA), for analysis. All referrals with an outcome of accepted or refused were included in the analysis, even if all data fields were not completed for the referral. Where missing data fields were encountered, these fields were excluded from the analysis of that parameter with the completed data fields forming the total.

Categorical variables were described as percentages and compared using the $\chi^{2}$ test or Fisher's exact test, where appropriate. The Bonferroni correction was applied where appropriate. Continuous data were described using means and standard deviations when normally distributed and medians and interquartile ranges (IQRs) when the distribution was non-Gaussian. These data were compared using the independentsamples $t$-test or the Mann-Whitney $U$-test, respectively. Factors identified as significant on univariate analysis were then included in a multivariable analysis using binary logistic regression to identify significant

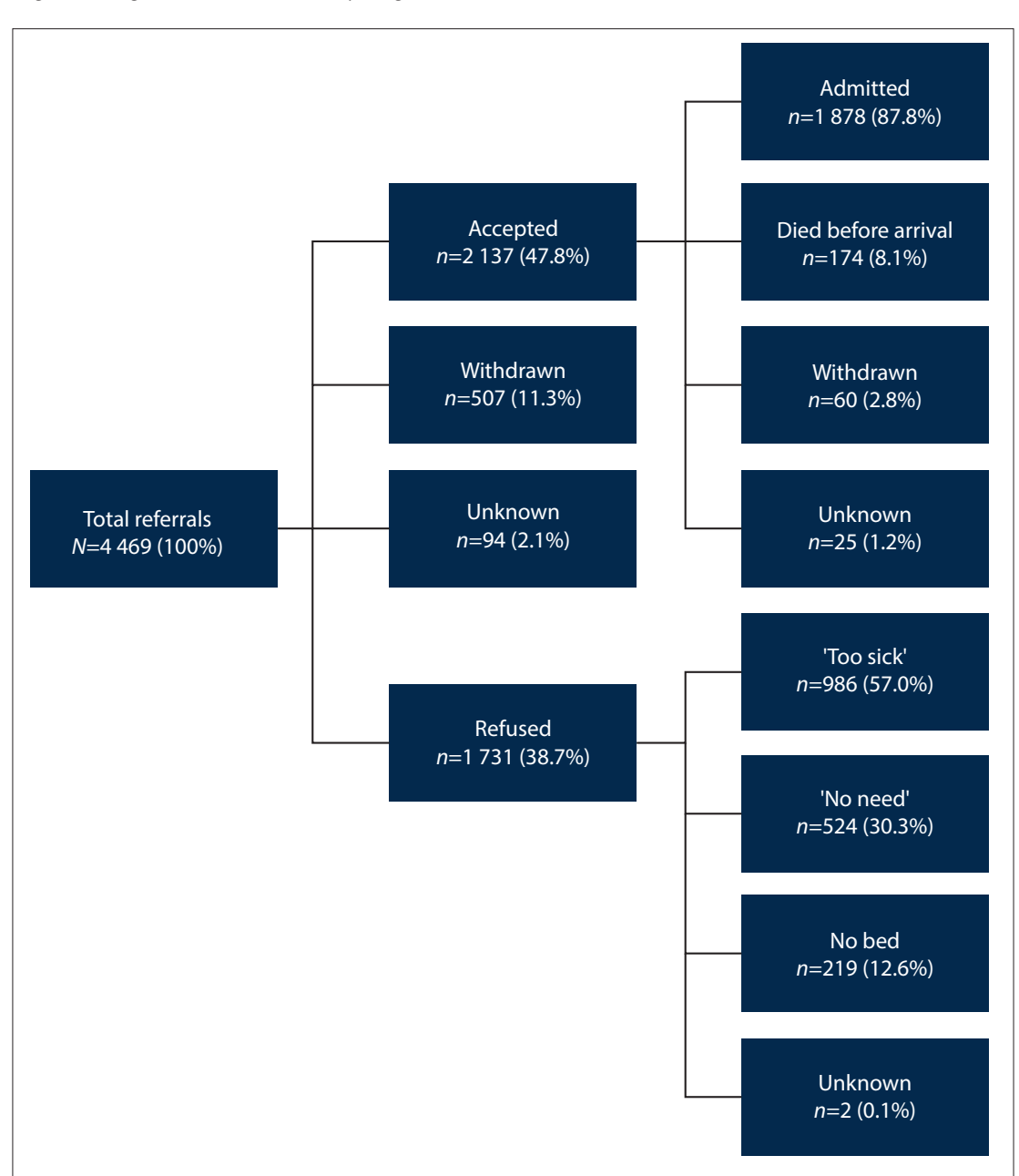

Fig. 1. Summary of outcomes of referrals. were common to the entire cohort were included in the multivariable analysis (e.g. age, comorbidities), with variables only applicable to certain cohorts being excluded (e.g. primary medical diagnosis). Significance was set at $p<0.05$.

\section{Results}

A total of 4469 referrals were received over the 48-month period studied. Of these, 507 (11.3\%) were withdrawn before a final decision of acceptance or refusal and $94(2.1 \%)$ had an unknown outcome, leaving 3868 referrals where an acceptance/ refusal decision was made as our study cohort (Fig. 1). Of these patients, $51.8 \%$ were female (unknown $n=8$ ). The median age of the study cohort was 38 years (range 1 103, IQR 27 - 56) for patients whose age was documented (unknown $n=61$ ). Children aged $<12$ years constituted $1.0 \%(n=38)$ of the referrals. Of the referred patients for whom an assumed race was noted, $73.8 \%$ were black African, $15.5 \%$ Indian and $10.7 \%$ white/ mixed race (unknown $n=71$ ). A complete distribution of data is reflected in Table 1. independent factors. Only variables that 
Table 1. Univariate analysis of general factors as per acceptance or refusal of ICU referrals

\begin{tabular}{|c|c|c|c|c|}
\hline Factors & $\begin{array}{l}\text { Total }(N=3868), \\
n(\text { column \%) }\end{array}$ & $\begin{array}{l}\text { Accepted }(N=2137), \\
n(\text { row } \%)^{*}\end{array}$ & $\begin{array}{l}\text { Refused }(N=1731), \\
n(\text { row } \%)^{*}\end{array}$ & $p$-value \\
\hline Age (years), median (IQR) & $38(27-56)$ & $35(25-53)$ & $43(30-60)$ & $<0.001$ \\
\hline Day & & & & 0.031 \\
\hline Monday & $564(14.6)$ & $316(56.0)$ & $248(44.0)$ & \\
\hline Tuesday & $594(15.4)$ & $340(57.2)$ & $254(42.8)$ & \\
\hline Wednesday & $602(15.6)$ & $316(52.5)$ & $286(47.5)$ & \\
\hline Thursday & $561(14.6)$ & $292(52.0)$ & $269(48.0)$ & \\
\hline Friday & $507(13.2)$ & $262(51.7)$ & $245(48.3)$ & \\
\hline Saturday & $493(12.8)$ & $294(59.6)$ & $199(40.4)$ & \\
\hline Sunday & $534(13.9)$ & $312(58.4)$ & $222(41.6)$ & \\
\hline Month & & & & 0.014 \\
\hline January & $319(8.2)$ & $170(53.3)$ & $149(46.7)$ & \\
\hline February & $376(9.7)$ & $201(53.5)$ & $175(46.5)$ & \\
\hline March & $336(8.7)$ & $180(53.6)$ & $156(46.4)$ & \\
\hline April & $349(9.0)$ & $182(52.1)$ & $167(47.9)$ & \\
\hline May & $318(8.2)$ & $201(63.2)$ & $117(36.8)$ & \\
\hline June & $318(8.2)$ & $173(54.4)$ & $145(45.6)$ & \\
\hline July & $385(10.0)$ & $207(53.8)$ & $178(46.2)$ & \\
\hline August & $312(8.1)$ & $162(51.9)$ & $150(48.1)$ & \\
\hline September & $329(8.5)$ & $176(53.5)$ & $153(46.5)$ & \\
\hline October & $296(7.7)$ & $160(54.1)$ & $136(45.9)$ & \\
\hline November & $249(6.4)$ & $162(65.1)$ & $87(34.9)$ & \\
\hline December & $280(7.2)$ & $162(57.9)$ & $118(42.1)$ & \\
\hline Year & & & & 0.024 \\
\hline 2014 & $999(25.8)$ & $587(58.8)$ & $412(41.2)$ & \\
\hline 2015 & $932(24.1)$ & $490(52.6)$ & $442(47.4)$ & \\
\hline 2016 & $997(25.8)$ & $532(53.4)$ & $465(46.6)$ & \\
\hline 2017 & $940(24.3)$ & $528(56.2)$ & $412(43.8)$ & \\
\hline Race & & & & 0.784 \\
\hline Black & $2802(73.8)$ & $1553(55.4)$ & $1249(44.6)$ & \\
\hline White/mixed race & $407(10.7)$ & $228(56.0)$ & $179(44.0)$ & \\
\hline Indian & $588(15.5)$ & $335(57.0)$ & $253(43.0)$ & \\
\hline Gender & & & & 0.88 \\
\hline Female & $1999(51.8)$ & $1108(55.4)$ & $891(44.6)$ & \\
\hline Male & $1861(48.2)$ & $1027(55.2)$ & $834(44.8)$ & \\
\hline Internal v. external referral & & & & $<0.001$ \\
\hline Internal & $1657(42.9)$ & $989(59.7)$ & $668(40.3)$ & \\
\hline External & $2202(57.1)$ & $1143(51.9)$ & $1059(48.1)$ & \\
\hline Level of external referring hospital & & & & $<0.001$ \\
\hline Central/tertiary & $141(7.0)$ & $86(61.0)$ & $55(39.0)$ & \\
\hline District/clinic & $669(33.2)$ & $292(43.6)$ & $377(56.4)$ & \\
\hline Private & $40(2.0)$ & $30(75.0)$ & $10(25.0)$ & \\
\hline Regional & $1168(57.9)$ & $635(54.4)$ & $533(45.6)$ & \\
\hline Referring discipline & & & & $<0.001$ \\
\hline Medicine & $2101(54.4)$ & $964(45.9)$ & $1137(54.1)$ & \\
\hline O\&G & $425(11.0)$ & $285(67.1)$ & $140(32.9)$ & \\
\hline Surgery & $1335(34.6)$ & $883(66.1)$ & $452(33.9)$ & \\
\hline Premorbid function & & & & $<0.001$ \\
\hline Good & $2044(52.8)$ & $1327(64.9)$ & $717(35.1)$ & \\
\hline Poor & $425(11.0)$ & $119(28.0)$ & $306(72.0)$ & \\
\hline Unknown & $1399(36.2)$ & $691(49.4)$ & $708(50.7)$ & \\
\hline
\end{tabular}

Intrahospital referrals accounted for $42.9 \%(n=1657)$ of the patients. Of patients referred from outside the hospital, the majority were from regional hospitals $(57.9 \%, n=1$ 168). For the purposes of analysis, clinics were grouped with district, and central was grouped with tertiary. The monthly and annual distributions are reflected in Table 1, with statistically significant different acceptance rates for May 
and November. The primary referring discipline was medicine in 54.3\% of cases, surgery in $34.5 \%$ and obstetrics and gynaecology in $11 \%$. Seven cases were not classified. The primary disease was classified as trauma related in $11.7 \%$ of cases, sepsis related in $34.5 \%$ and non-communicable diseases in $53.2 \%$. The primary diagnosis in each of the three referring disciplines, as well as the sources of sepsis, are set out in Table 2.
According to the referring doctor's evaluation, premorbid functional status was classified as good $(52.8 \%)$, poor $(11.0 \%)$ or unknown to the referring doctor (36.2\%). HIV status was documented as positive (26.2\%), negative (13.8\%), and unknown (60.0\%), with $65.4 \%$ of positive patients on antiretroviral therapy (ART). Comorbidities, noted per organ/system, are set out in Table 3.

\begin{tabular}{|c|c|c|c|c|}
\hline Factors & Total, $\boldsymbol{n}$ (column \%) & Accepted, $n$ (row \%) & Refused, $n$ (row \%) & $p$-value \\
\hline Primary disease & & & & $<0.001$ \\
\hline Trauma & $453(11.8)$ & $330(72.8)$ & $123(27.2)$ & \\
\hline Sepsis & $1335(34.7)$ & $700(52.4)$ & $635(47.6)$ & \\
\hline Non-communicable & $2056(53.5)$ & $1087(52.9)$ & $969(47.1)$ & \\
\hline Primary medical diagnosis & & & & $<0.001$ \\
\hline Asthma & $76(3.6)$ & $52(68.4)$ & $24(31.6)$ & \\
\hline Cardiac failure & $211(10.1)$ & $89(42.2)$ & $122(57.8)$ & \\
\hline COPD & $105(5.0)$ & $40(38.1)$ & $65(61.9)$ & \\
\hline CVA & $55(2.6)$ & $7(12.7)$ & $48(87.3)$ & \\
\hline Diabetic ketoacidosis & $20(1.0)$ & $11(55.0)$ & $9(45.0)$ & \\
\hline Liver disease & $36(1.7)$ & $7(19.4)$ & $29(80.6)$ & \\
\hline Malaria & $13(0.6)$ & $8(61.5)$ & $5(38.5)$ & \\
\hline Myocardial infarction & $54(2.6)$ & $26(48.1)$ & $28(51.9)$ & \\
\hline Other & $231(11.0)$ & $102(44.2)$ & $129(55.8)$ & \\
\hline Poisoning & $279(13.3)$ & $195(69.9)$ & $84(30.1)$ & \\
\hline Pulmonary embolism & $14(0.7)$ & $6(42.9)$ & $8(57.1)$ & \\
\hline Renal failure & $182(8.7)$ & $79(43.4)$ & $103(56.6)$ & \\
\hline Sepsis & $737(35.2)$ & $299(40.6)$ & $438(59.4)$ & \\
\hline Status epilepticus & $81(3.9)$ & $37(45.7)$ & $44(54.3)$ & \\
\hline Total & $2094(100)$ & $958(45.7)$ & $1136(54.3)$ & \\
\hline Primary surgical diagnosis & & & & $<0.001$ \\
\hline Bowel obstruction & $23(1.7)$ & $20(87.0)$ & $3(13.0)$ & \\
\hline Burns & $35(2.6)$ & $15(42.9)$ & $20(57.1)$ & \\
\hline Crush syndrome & $29(2.2)$ & $20(69.0)$ & $9(31.0)$ & \\
\hline Elective surgery & $44(3.3)$ & $22(50.0)$ & $22(50.0)$ & \\
\hline Other non-surgical & $81(6.1)$ & $44(54.3)$ & $37(45.7)$ & \\
\hline Other surgical & $146(11.0)$ & $84(57.5)$ & $62(42.5)$ & \\
\hline Pancreatitis & $41(3.1)$ & $28(68.3)$ & $13(31.7)$ & \\
\hline Sepsis & $443(33.3)$ & $291(65.7)$ & $152(34.3)$ & \\
\hline Trauma & $453(34.0)$ & $330(72.8)$ & $123(27.2)$ & \\
\hline Upper GI bleed & $37(2.8)$ & $26(70.3)$ & $11(29.7)$ & \\
\hline Total & $1332(100)$ & $880(66.1)$ & $452(33.9)$ & \\
\hline Primary O\&G diagnosis & & & & 0.019 \\
\hline Antepartum haemorrhage & $26(6.2)$ & $20(76.9)$ & $6(23.1)$ & \\
\hline Eclampsia & $92(22.1)$ & $60(65.2)$ & $32(34.8)$ & \\
\hline Other & $123(29.5)$ & $69(56.1)$ & $54(43.9)$ & \\
\hline Postpartum haemorrhage & $39(9.4)$ & $31(79.5)$ & $8(20.5)$ & \\
\hline Sepsis & $137(32.9)$ & $98(71.5)$ & $39(28.5)$ & \\
\hline Total & $417(100)$ & $278(66.7)$ & $139(33.3)$ & \\
\hline Source of sepsis & & & & $<0.001$ \\
\hline Abdomen & $348(26.1)$ & $248(71.3)$ & $100(28.7)$ & \\
\hline Central nervous system & $62(4.6)$ & $25(40.3)$ & $37(59.7)$ & \\
\hline CAP & $621(46.5)$ & $281(45.2)$ & $340(54.8)$ & \\
\hline HAP & $137(10.3)$ & $69(50.4)$ & $68(49.6)$ & \\
\hline Lines & $1(0.1)$ & 0 & $1(100)$ & \\
\hline Skin/soft tissue & $149(11.2)$ & $66(44.3)$ & $83(55.7)$ & \\
\hline Systemic/blood & $13(1.0)$ & $8(61.5)$ & $5(38.5)$ & \\
\hline Urine & $4(0.3)$ & $3(75.0)$ & $1(25.0)$ & \\
\hline
\end{tabular}


Table 3. Univariate analysis of comorbidities according to acceptance or refusal of ICU referrals

\begin{tabular}{lllll}
\hline Comorbidity & Total, $\boldsymbol{n}$ (column \%) & Accepted, $\boldsymbol{n}$ (row \%) & Refused, $\boldsymbol{n}$ (row \%) & $\boldsymbol{p}$-value \\
\hline HIV & & & & $<0.001$ \\
$\quad$ Negative & $531(13.7)$ & $335(63.1)$ & $196(36.9)$ & \\
$\quad$ Positive & $1015(26.2)$ & $425(41.9)$ & $590(58.1)$ & \\
$\quad$ Unknown & $2322(60.0)$ & $1377(59.3)$ & $945(40.7)$ & \\
ART & & & \\
$\quad$ No & $270(26.6)$ & $118(43.7)$ & $152(56.3)$ & \\
$\quad$ Unknown & $81(8.0)$ & $36(44.4)$ & $45(55.6)$ & $<38$ \\
$\quad$ Yes & $664(65.5)$ & $271(40.8)$ & $393(59.2)$ & $<0.001$ \\
Opportunistic infection & $331(32.6)$ & $91(27.5)$ & $240(72.5)$ & 0.001 \\
Hypertension & $879(22.7)$ & $434(49.4)$ & $445(50.6)$ & $<0.001$ \\
Ischaemic heart disease & $110(2.8)$ & $44(40.0)$ & $66(60.0)$ & $<0.001$ \\
Cardiac failure & $172(4.4)$ & $60(34.9)$ & $112(65.1)$ & 0.001 \\
COPD & $148(3.8)$ & $60(40.5)$ & $88(59.5)$ & 0.01 \\
PTB & $225(5.8)$ & $84(37.3)$ & $141(62.7)$ & 0.019 \\
Asthma & $138(3.6)$ & $91(65.9)$ & $47(34.1)$ & 0.005 \\
Interstitial lung disease & $13(0.3)$ & $3(23.1)$ & $10(76.9)$ & 0.001 \\
CVA & $72(1.9)$ & $28(38.9)$ & $44(61.1)$ & 0.946 \\
Psychiatric disorder & $89(2.3)$ & $65(73.0)$ & $24(27.0)$ & 0.035 \\
Epilepsy & $82(2.1)$ & $45(54.9)$ & $37(45.1)$ & $<0.001$ \\
Diabetes mellitus & $563(14.6)$ & $288(51.2)$ & $275(48.8)$ & $<0.001$ \\
Chronic kidney disease & $227(5.9)$ & $85(37.4)$ & $142(62.6)$ &
\end{tabular}

Table 4. Multivariable analysis of significant factors for

\begin{tabular}{|c|c|c|}
\hline Factors & OR $(95 \% \mathrm{CI})$ & $p$-value \\
\hline Age & $1.02(1.01-1.02)$ & $<0.001$ \\
\hline Level of referring hospital & & 0.001 \\
\hline Central/tertiary & 1 & \\
\hline District/clinic & $1.06(0.69-1.62)$ & \\
\hline Private & $0.27(0.11-0.62)$ & \\
\hline Regional & $1.20(0.80-1.79)$ & \\
\hline Referring discipline & & $<0.001$ \\
\hline Surgery & 1 & \\
\hline Medicine & $2.02(1.66-2.46)$ & \\
\hline O\&G & $1.12(0.84-1.50)$ & \\
\hline Premorbid function & & $<0.001$ \\
\hline Good & 1 & \\
\hline Poor & $3.20(2.45-4.17)$ & \\
\hline Unknown & $1.64(1.40-1.92)$ & \\
\hline Comorbidity HIV & & $<0.001$ \\
\hline Negative & 1 & \\
\hline Positive & $2.22(1.73-2.83)$ & \\
\hline Unknown & $1.15(0.91-1.44)$ & \\
\hline Comorbidity malignancy & $2.05(1.26-3.34)$ & 0.004 \\
\hline Comorbidity cardiac failure & $1.52(1.06-2.19)$ & 0.023 \\
\hline Comorbidity asthma & $0.48(0.32-0.72)$ & $<0.001$ \\
\hline Comorbidity psychiatric disease & $0.38(0.23-0.65)$ & $<0.001$ \\
\hline
\end{tabular}

The outcomes of the referrals are reflected in Fig. 1, with 38.7\% of patients refused admission. The commonest reason for refusal (57.0\%) was assessment of patients by the admitting specialist as being 'too sick'. Our readmission rate was 56/1 878 (3.0\%).
Univariate analysis identified the following factors as significant for refusal of admission: age, day, month, year, external referrals, level of referring hospital, referring discipline, primary disease classification, primary medical/surgical/obstetrics and gynaecology diagnosis, source of sepsis, premorbid function, HIV status, presence of active opportunistic infection, and all comorbidities (except epilepsy). Sex $(p=0.88)$, race $(p=0.784)$, use of ART $(p=0.638)$ and epilepsy $(p=0.946)$ were not significant on univariate analysis (Tables 1 - 3).

Multivariable analysis identified age, referring discipline as medicine, poor or unknown premorbid functioning, and comorbidities of HIV, malignancy and cardiac failure as significant factors for the refusal of admission of patients to the ICU. Referrals were significantly more likely to be accepted from private institutions, and if the comorbidity was asthma or psychiatric disease. Details are reflected in Table 4. The Hosmer and Lemeshow test of goodness of fit had a $p$-value $=0.555$, with Nagelkerke $R^{2}=0.191$.

\section{Discussion}

As a hierarchical health system exists in KZN, with patients referred up the chain from a clinic to a district hospital, and thence to regional, tertiary and central hospitals, the mean of 93.1 referrals per month that were received during the study period may well not reflect the burden of critical care diseases in the province. With the shortage of ICU beds in the province well known, triage decisions are often made earlier, before patients are referred to an ICU. Most of the referrals came from within the hospital. The $0.7 \%$ of all referrals that came from other tertiary and central hospitals may reflect the burden on these hospitals, which have functional ICUs. The referrals from district and other regional hospitals are different, as many of these facilities do not have functional ICUs. The lower mean age in comparison with high-income countries may reflect a different disease profile and life expectancy. ${ }^{[4]}$ 
Table 5. Summary of South African studies indicating ICU referral outcomes with reasons for refusal

\begin{tabular}{|c|c|c|c|c|c|c|c|}
\hline & & Total referrals, & & & & & \\
\hline Reference & Year & $N$ & Accepted, $n(\%)$ & Refused, $n(\%)$ & Full, $n(\%)$ & Too well, $n(\%)$ & Too sick, $n(\%)$ \\
\hline Burrows $^{[6]}$ & 1994 & 264 & $140(53.0)$ & $124(47.0)$ & $56(21.2)$ & $47(17.8)$ & $22(8.3)$ \\
\hline Gopalan et al..$^{[7]}$ & 1998 & & & & & & \\
\hline Hospital $1^{*}$ & & 58.8 & $36.6(62)$ & $21.9(38)$ & $12(20)$ & $7.1(12)$ & $2.8(5)$ \\
\hline Hospital $2^{*}$ & & 77.4 & $60.1(78)$ & $17.2(22)$ & $15.3(20)$ & $1.3(2)$ & $0.6(1)$ \\
\hline Gordon et al. ${ }^{[8]}$ & 2015 & 2081 & $1499(72.0)$ & $582(28.0)$ & $588(28.3)^{\dagger}$ & $312(15.0)$ & $270(13.0)$ \\
\hline Present study & 2018 & 3868 & 2137 (55.2) & $1731(45.9)^{\ddagger}$ & $219(5.7)$ & $524(13.5)$ & $986(25.5)$ \\
\hline
\end{tabular}

Table 5 compares referrals in the present study with those in previous studies conducted in KZN. Our refusal rate of $45 \%$ is high in comparison with rates of other published SA data. These studies were conducted at different times and may reflect a changing situation in the health service.

The rate of withdrawn referrals (11.3\%) may be deemed high. The high withdrawal rate may indicate too early or inappropriate referrals where the patients are actually too well, with the consult subsequently withdrawn, or too late or inappropriate referrals where the patients die before a definitive decision. For more appropriate referral processes and decisions to occur, there is a need for a narrowing of the gap between teams referring patients and the ICU team accepting patients with regard to resources, capabilities and expectations of each.

The 'too sick' group of patients constituted $25.5 \%$ of all referred patients. It represents a high proportion, but may in part be explained by the inclusion in this group of both patients for whom ICU admission was deemed futile (non-beneficial) and patients who would derive minimal benefit and were therefore triaged. In resource-constrained environments such as ours, the benefit to be derived needs to be significant in order to tip the balance of triage decisions towards acceptance rather than refusal. Consequently, patients deemed 'too sick' in such environments may well have been considered appropriate and accepted in better-resourced settings. The line defining the 'too sick' is therefore resource dependent.

The issue of race in general medical decision-making remains contentious, but has not been explored in ICU admission decisions. ${ }^{[10]}$ Race is not recorded on our referral forms. We nevertheless attempted to evaluate race as a factor in this study by ascribing race status according to patient names. This approach has limitations, but in an environment such as ours, where there is usually a distinct association between ethnic group and name, we felt that it was reasonable to take this approach. Although we were not able to validate the veracity of these data, no association between race and admission decisions was shown.

In our analysis, age was a significant factor for admission/refusal decisions. However, the evidence for age as a factor in these decisions is not conclusive in the literature, with some studies showing an association $^{[11-15]}$ and others showing no association. ${ }^{[16-19]}$ Some authors have suggested that age alone should not be used as a factor when considering admission. ${ }^{[20]}$ The physiological age of a patient, or an assessment of frailty, may be more important than chronological age. ${ }^{[21]}$ Even though age was considered as a factor in admission decisions in another study, $95.1 \%$ of physicians indicated that a definitive age criterion precluding ICU admission should not be instituted. ${ }^{[22]}$

There is no obvious explanation for the lower likelihood of refusing patients admission in May and November over the 48 months, as there is no correlation with the normal seasonal variation of patient illness.
Refusal of admission was less likely if the patient was from within the hospital, as we would have been the first point of referral and these patients were assessed by the ICU team on site. This bias towards in-hospital patients is supported by the work of Garrouste-Orgeas et al. ${ }^{[14]}$ who identified triage at the hospital and triage by a senior intensivist as being significant for the admission/refusal decision. The lower likelihood of refusing patients from district hospitals may be explained by these hospitals not having their own ICUs and therefore needing to consult up the referral chain. Such referrals may be viewed sympathetically and expedited quickly, as these hospitals have limited resources and expertise. Our higher likelihood of accepting patients from the private sector relates to reducing the financial burden on patients' families, as these patients are invariably referred to the public sector once their medical insurance funds have been exhausted.

In our study, patients from internal medicine were two times more likely to be refused in comparison with surgical patients. Historically, the unit was primarily a surgical ICU, a bias that may be retained. Further, there may be a perception of better outcomes in surgical patients, in whom the pathology may be considered reversible. The negative profile of our medical patient referral population in respect of high rates of HIV, pulmonary tuberculosis (PTB) and other comorbidities may also have contributed to this finding.

The strongest predictor of refusals in our study was poor premorbid functioning of patients, which increased the likelihood more than three-fold. The impact of premorbid functioning is strongly supported by other studies, where baseline function was considered to be a good index of prognosis of ICU survival. ${ }^{[13,14,23,24]}$ Unknown premorbid functioning was also significantly more likely to lead to refusal in comparison with good premorbid functioning. There is no obvious explanation for this finding. Possible reasons may include incomplete disclosure of a patient's poor premorbid function by the referring doctor as 'unknown' so as to increase the chances of acceptance, and inability to determine premorbid function, indirectly reflecting the severity of illness of the patient (e.g. unconscious patient) or the social/family support of the patient (e.g. unaccompanied patient with no collateral history). The high rate of 'unknown' responses from the referring doctors may also reflect their lack of appreciation of the importance of premorbid function as a factor in prognostication. The functioning in our study was a subjective assessment by the referring doctor, which may have been inconsistent and inaccurate.

The presence and severity of comorbidities have been consistently identified as factors affecting admission decisions. ${ }^{[13-15,23]}$ Malignancy, HIV, cardiac failure and PTB were associated with increased odds of refusal, while asthma was associated with lower odds. Malignancies and HIV positivity increased the chances of refusal more than twofold. The severity or staging of these conditions was not correlated with the admission decision. The increased chance of acceptance 
with asthma may relate to the reversibility of the condition and consequently a probable better prognosis.

\section{Study limitations}

Limitations with our study are noted. This was a retrospective study, and severity of illness, consistently identified as a factor in admission decisions, was not considered. In addition, other factors such as time of admission and number of beds at the time of the consult were not considered, as these fields have only been recently added to the data collection. The classification of patients as 'too sick' did not draw a distinction between patients deemed 'futile or non-beneficial' (i.e. those who would derive no benefit from ICU admission and are likely to die with or without intensive care) and triaged patients, where some degree of benefit, even if minimal, could be derived. Classification as per the Society of Critical Care Medicine prioritisation model may be more effective in truly distinguishing between the various groups. ${ }^{[21]}$ Premorbid functioning, identified as the factor with the strongest association with refusal, was not objectively quantified and relied on the subjective assessment of the referring doctor.

\section{Conclusions}

A better understanding of factors affecting admission/refusal decisions in patients referred for ICU admission will allow for a more effective and appropriate referral process and a more rational utilisation of scarce ICU resources. We have a demonstrated a high refusal rate of more than one in three referrals and have identified age, intrahospital referral, poor premorbid functioning, and comorbidities of HIV, malignancy, cardiac failure and PTB as significant factors resulting in refusal of admission of patients to our ICU. A higher refusal rate of medical v. surgical referrals may illustrate a bias towards a perceived better outcome for surgical patients. In contrast, the lack of influence of race suggests the absence of racial bias. Further prospective studies are necessary to elucidate fully the impact of various other factors.

Declaration. None.

Acknowledgements. All staff of King Edward VIII Hospital ICU.

Author contributions. PDG: all aspects; KdV: all aspects.

Funding. None.

Conflicts of interest. None.
1. Blanch L, Abillama FF, Amin P, et al.; Council of the World Federation of Societies of Intensive and Critical Care Medicine. Triage decisions for ICU admission: Report from the Task Force of the World Federation of Societies of Intensive and Critical Care Medicine. J Crit Care 2016;36:301-305. https://doi Federation of Societies of Intensich
org/10.1016/j.jcrc.2016.06.014

2. Brg/10.1016/j.jcrcc.2016.06.014 constraint. In: Padarath A, Barron P, eds. South African Health Review 2017. Durban: Health Systems
che Trust, 2017. http://www.hst.org.za/publications/south-african-health-review-2017 (accessed 16 March 2018)

3. Bhagwanjee S, Scribante J. National audit of critical care resources in South Africa - unit and bed distribution. S Afr Med J 2007;97(12):1311-1314.

4. Prin $\mathrm{M}$, Wunsch $\mathrm{H}$. International comparisons of intensive care: Informing outcomes and improving standards. Curr Opin Crit Care 2012;18(6):700-706. https://doi.org/10.1097/MCC.0b013e32835914d5

5. Rhodes A, Ferdinande P, Flaatten H, et al. The variability of critical care bed numbers in Europe. Intensive Care Med 2012;38(10):1647-1653. https://doi.org/10.1007/s00134-012-2627-8

6. Burrows RC. Removal of life support in intensive care units. Med Law 1994;13(3):489-500

7. Gopalan PD, Bhagwanjee S, Burrows RC. Referral patterns of two intensive care units in the Greater Gopalan PD, Bhagwanjee S, Burrows RC. Re
Durban area. S Afr Med J 1998;88(11):1452.

8. Gordon K, Allorto N, Wise R. An analysis of referrals and triage patterns in a South African metropolitan Gordon K, Allorto N, Wise R. An analysis of referrals and triage patterns in a South African metropol
adult intensive care service. S Afr Med J 2015;105(6):491-495. https://doi.org/10.7196/SAMI.9007

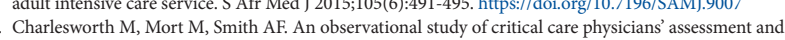
Charlesworth M, Mort M, Smith AF. An observational study of critical care physicians assessment and
decision-making practices in response to patient referrals. Anaesthesia 2017;72(1):80-92. https://doi. org/10.1111/anae. 13667

10. Dehon $\mathrm{E}$, Weiss $\mathrm{N}$, Jones J, et al. A systematic review of the impact of physician implicit racial bias on clinical decision making. Acad Emerg Med 2017;24(8):895-904. https://doi.org/10.1111/acem.13214

11. Joynt GM, Gomersall CD, Tan P, et al. Prospective evaluation of patients refused admission to an intensive care unit: Triage, futility and outcome. Intensive Care Med 2001;27(9):1459-1465. https://doi. org/10.1007/s001340101041

2. Sprung CL, Geber D, Eidelman LA, et al. Evaluation of triage decisions for intensive care admission. Crit Care Med 1999;27(6):1073-1079. https://doi.org/10.1097/00003246-199906000-00021

13. Azoulay E, Pochard F, Chevret S, et al. Compliance with triage to intensive care recommendations. Crit Care Med 2001;29(11):2132-2136. https://doi.org/10.1097/00003246-200111000-00014

14. Garrouste-Orgeas M, Montuclard L, Timsit J-F, et al. Triaging patients to the ICU: A pilot study of factors influencing admission decisions and patient outcomes. Intensive Care Med 2003;29(5):774-781. factors influencing admission decisions and

15. Escher M, Perneger TV, Chevrolet JC. National questionnaire survey on what influences doctors' Escher M, Perneger TV, Chevrolet JC. National questionnaire survey on what influences doctors'
decisions about admission to intensive care. BMJ 2004;329(7463):425. https://doi.org/10.1136 decisions about admission to intensive care. BMJ 2004;329(7463):425. https://doi.org/10.1136/
bmi.329.7463.425 bmj.329.7463.425

16. Orsini J, Blaak C, Yeh A, et al. Triage of patients consulted for ICU admission during times of ICU-bed shortage. J Clin Med Res 2014;6(6):463-468. https://doi.org/10.14740/jocmr1939w

17. Orsini J, Butala A, Ahmad N, et al. Factors influencing triage decisions in patients referred for ICU admission. J Clin Med Res 2013;5(5):343-349. https://doi.org/10.4021/jocmr1501w

18. Cohen RI, Eichorn A, Silver A. Admission decisions to a medical intensive care unit are based on functional status rather than severity of illness: A single center experience. Minerva Anestesiol 2012;78(11):1226-1233. https://www.minervamedica.it/en/journals/minerva-anestesiologica/article. php?cod=R02Y2012N11A1226 (accessed 5 August 2019)

19. Howe DC. Observational study of admission and triage decisions for patients referred to a regional intensive care unit. Anaesth Intensive Care 2011;39(4):650-658. https://doi. org/10.1177/0310057X1103900419

20. Marik PE. Should age limit admission to the intensive care unit? Am J Hosp Palliat Care 2007;24(1):6366. https://doi.org/10.1177\%2F1049909106295385

21. Nates JL, Nunnally M, Kleinpell R, et al. ICU admission, discharge, and triage guidelines: A framework to enhance clinical operations, development of institutional policies, and further research. Crit Care Med 2016:44(8);1553-1602. https://doi.org/10.1097/CCM.0000000000001856

22. Nuckton TJ, List ND. Age as a factor in critical care unit admissions. Arch Intern Med 1995;155(10):10871092

23. Einav S, Soudry E, Levin PD, et al. Intensive care physicians' attitudes concerning distribution of intensive care resources: A comparison of Israeli, North American and European cohorts. Intensive Care Med 2004;30(6):1140-1143. https://doi.org/10.1007/s00134-004-2273-x

24. James FR, Power N, Laha S. Decision-making in intensive care medicine - a review. J Intensive Care Soc 2018;19(3):247-258. https://doi.org/10.1177/1751143717746566 